\title{
The Many Facets of Economic Mobility
}

Gary S. Fields

\section{Introduction}

The famed economist Joseph Schumpeter likened income distributions to the rooms in a hotel. ${ }^{1}$ The rooms at the top are luxurious, those in the middle are ordinary, and those in the basement are substandard. On any given night, the occupants of the hotel experience quite unequal accommodations. Later, though, the same people are found to be in different rooms (or, equivalently, the same rooms are found to have different people in them). The difference in the quality of the hotel rooms at each point in time is what we call inequality. The constant quality of each room means that there is no growth, positive or negative. The movement of hotel guests among different quality rooms constitutes mobility, which is the topic of this chapter.

Schumpeter's hotel analogy raises some fundamental questions about what economic mobility is, how it relates to inequality and how both relate to economic growth. There is no question that the movement of guests among rooms is an aspect of mobility. But is that all there is to mobility? If the existing furnishings are moved from some rooms to others, is there mobility then? What if the hotel is refurbished so that some of the rooms are made nicer? Do the lucky residents of these rooms enjoy upward mobility? As for those whose rooms are not upgraded, do they suffer downward mobility because they are now in a relatively worse position?

The main point of this chapter is to show that the different indices used in the mobility literature are not measures of the same underlying conceptual entity. ${ }^{2}$ In elementary statistics, students are taught that the mean and median are both measures of central tendency but they are different measures of central tendency; the variance and Gini coefficient are measures of dispersion but they are different measures of dispersion; and central tendency and dispersion are fundamentally different concepts from one another. In much the same way, this chapter maintains that the different mobility indices in common use are measuring fundamentally different mobility concepts from one another. It is in this sense that mobility really is multifaceted. 
The term 'mobility' connotes precise ideas to various researchers, but it connotes different precise ideas to different researchers. Furthermore, these differences remain even after agreeing on a number of other aspects of the mobility under discussion. These other aspects, discussed in the following paragraphs, are whether the context is intergenerational or intragenerational, what is the indicator of social or economic status and whether the study is at the macro-mobility or micro-mobility level.

One issue is whether the aspect of mobility of interest is intergenerational or intragenerational. In the intergenerational context, the recipient unit is the family, specifically a parent and a child. In the intragenerational context, the recipient unit is the individual or family at two different dates. The analysis in this chapter applies equally to both.

Once the context has been decided upon, a second issue to be decided is, indicator of what among whom? The indicator could be income, consumption, labour market earnings, occupation, education, or any of a number of other indicators for a given recipient unit. The recipient unit may be an individual, a worker, a family, a per capita, or an adult equivalent. For brevity, the discussion below is phrased in terms of economic well-being (denoted 'income') among recipient units (denoted 'individuals') with the understanding that the analysis is equally applicable to any of the other status indicators and recipient units mentioned above.

Third, mobility research may be conducted at two levels, macro and micro. Macro mobility studies start with the question, 'How much economic mobility is there?' Answers are of the type; 'a per cent of the people stay in the same income quintile', ' $b$ per cent of the people moved up at least $\$ 1,000$ while $c$ per cent of the people moved down at least $\$ 1,000^{\prime}$ ', 'the mean absolute value of income change was $\$ d^{\prime}$ and 'in a panel of length $T$, the mean number of years in poverty is $t^{* \prime}$. The macro mobility studies often go beyond this question to ask, 'Is economic mobility higher here than there and what accounts for the difference?' Answers would be of the type; 'economic mobility has been rising over time', 'A has more upward mobility than $B$ because economic growth was higher in $A$ than in $B$ ' and 'incomes are more stable in $C$ than in $D$ because $C$ has a better social safety net'. Micro mobility studies, on the other hand, start with the question, 'What are the correlates and determinants of the income changes of individual income recipients?' The answers to these questions would be of the type; 'unconditionally, income changes are higher for the better educated' and 'other things equal, higher initial income is associated with lower subsequent income growth'.

This chapter addresses macro mobility. The issues raised here are applicable to both economic and social mobility, to intergenerational and intragenerational mobility, and to mobility of individuals and of families. This work shows that mobility, growth and inequality are related but distinct concepts. Two simple examples are used to highlight the differences. 
It is then demonstrated that in macro mobility studies, there are actually six fundamentally different concepts that are being measured. They are time-dependence, positional movement, income flux, directional income movement, movement of income shares, and mobility as an equalizer of longer-term incomes.

The chapter then turns to the question: Does it make a practical difference which income concept is measured? The most fundamental macro mobility questions are these: (1) Has mobility been rising or falling over time?; (2) Which group has more income mobility than another? Panel data drawn from the Panel Study of Income Dynamics in the United States and the Déclarations Annuelles de Données Sociales and the Echantillon Démographique Permanent in France are used to demonstrate that the answers to even these most fundamental questions depend on the mobility concept used. In both countries, mobility has been falling for some mobility concepts but not for others. In both countries, women have more mobility than men for some concepts but men have more mobility than women for others, and likewise the better educated have more mobility than others for some mobility concepts and less mobility for others.

The chapter closes with a brief conclusion. The major point is that before social scientists 'do a mobility study', it is necessary to be very clear about the mobility concept or concepts we wish to study. As this work shows, the choice can and does make a vital difference.

\section{Mobility, inequality, and growth: two examples}

In Schumpeter's hotel model, it is known which guest occupies which room on any given night. In the real world, such information can be obtained only from panel data, in which each individual is observed at two or more points in time. When such data are available and the guest-room pairings over a number of nights can be observed, the long-term equality of accommodations can be compared with the equality of accommodations on any given night. It is apparent in this example that the greater is the movement of guests among rooms of fixed quality, the greater is the long-term equality of accommodations.

Suppose such panel data had not been available but the data consisted only of comparable cross sections. Nothing could have been said about mobility or inequality in the longer run. It would only have been possible to have compared the inequality of accommodations at each point in time. The only lesson such a comparison could have produced is that inequality was unchanged.

Another example may also be considered. Suppose samples of two persons were to be drawn from an economy in a base year and a final year, and the incomes of each person in each of the two years were to be measured. Assume the data are drawn from comparable cross sections in the two years but that 
the individuals sampled are not the same in the two years (or if they are the same, the surveys do not record who is who). Let the distribution of income in the base year be $y_{1}=(1,3)$ and in the final year $y_{2}=(1,5)$. In a very straightforward sense, one would be justified in saying that the change in the income distribution from $y_{1}=(1,3)$ to $y_{2}=(1,5)$ entails economic growth, but the growth that takes place raises inequality.

What can be said about economic mobility from such anonymous data? Very simply: nothing. This is because the data are anonymous, and so the analyst does not know which income recipient is which. ${ }^{3}$

In this little example, there are only two underlying possibilities: either the two individuals occupied the same positions in each period or they swapped positions. Adopt the notational convention of arraying income recipients in some order in the base year distribution, keep these identified individuals in the same position in the final year, and denote the movement from a base year personalized vector to a final year personalized vector by $\rightarrow$. The two possible patterns of longitudinal income changes consistent with $y_{1}$ becoming $y_{2}$ may then be denoted:

(a) $(1,3) \rightarrow(1,5)$

and

(b) $(1,3) \rightarrow(5,1)$.

Do situations (a) and (b) have the same economic mobility as one another? Many observers would say that they do not.

More difficult, though, is the question, how specifically do the two mobility situations differ? To answer this question, one must have a clear idea of what is meant by economic mobility. Let us now turn now to six mobility concepts that have been used in the literature.

\section{Six mobility concepts}

The mobility literature is plagued by people using the same term 'economic mobility' (or 'social mobility') to mean different things. Six notions of mobility need to be distinguished. Briefly, they are: time-dependence, which measures the extent to which economic well-being in the past determines individuals' economic well-being at present; positional movement, which is what we measure when we look at individuals' changes in economic positions (ranks, centiles, deciles, or quintiles); share movement, which arises when individuals' shares of the total income change; income flux, which is what we gauge when we look at the size of the fluctuations in individuals' incomes but not their sign; directional income movement, which is what we measure when we determine how many people move up or down how many dollars; and mobility as an equalizer of longer-term incomes, which involves comparing the inequality of income at one point in time with the inequality of income over a longer period.

Let us now look at each of these in greater detail. 


\section{Time-independence}

Time-dependence is the notion that incomes at present are determined by incomes in the past. Time-dependence is highest when income at present is entirely determined by past income. As the economy moves further away from this deterministic situation, it gets closer to the situation where current income is independent of past income. The notion of mobility as timeindependence is that mobility is greatest when current and past income are unrelated to one another.

A common way of gauging time-dependence and -independence is by constructing a quantile mobility matrix. (A quantile mobility matrix classifies people in each year according to fixed categories such as five equal-sized quintiles or ten equal-sized deciles, with base year quantile determining the row and final year quantile determining the column. Each entry is the probability that, starting in a given row, the individual ends up in a given column.) If incomes were perfectly positively time-dependent, the quantile transition matrix would have all entries lying along the principal diagonal, and thus the transition matrix would be an identity matrix. For example:

$$
P_{1}=\left[\begin{array}{lllll}
1 & 0 & 0 & 0 & 0 \\
0 & 1 & 0 & 0 & 0 \\
0 & 0 & 1 & 0 & 0 \\
0 & 0 & 0 & 1 & 0 \\
0 & 0 & 0 & 0 & 1
\end{array}\right]
$$

(A theoretical possibility, never observed in practice, is negative timedependence, the limiting value of which is when final year quantile is inversely related to base year quantile. If such a case were to be observed, the transition matrix would be a mirror image of $P_{1}$.)

Suppose that instead of perfect time-dependence, incomes were time-independent. Again taking the example of classifying people into income quintiles, perfect time-independence would mean that 20 per cent of those in each base year income quintile would be found in each final year income quintile, producing the following quintile transition matrix:

$$
P_{2}=\left[\begin{array}{lllll}
0.2 & 0.2 & 0.2 & 0.2 & 0.2 \\
0.2 & 0.2 & 0.2 & 0.2 & 0.2 \\
0.2 & 0.2 & 0.2 & 0.2 & 0.2 \\
0.2 & 0.2 & 0.2 & 0.2 & 0.2 \\
0.2 & 0.2 & 0.2 & 0.2 & 0.2
\end{array}\right]
$$

In order to be able to implement the notion of mobility as timeindependence, one needs a way of measuring how close an actual transition matrix is to these theoretical possibilities. In the case of a quintile transition matrix, the number of people in cell $i$, $j$ under time-independence is the $P_{2}$ matrix multiplied by an appropriate scaling factor such that the sum of 
the expected frequencies is the total sample size $\mathrm{N}$ :

$$
P_{3}=\left[\begin{array}{lllll}
.04 \mathrm{~N} & .04 \mathrm{~N} & .04 \mathrm{~N} & .04 \mathrm{~N} & .04 \mathrm{~N} \\
.04 \mathrm{~N} & .04 \mathrm{~N} & .04 \mathrm{~N} & .04 \mathrm{~N} & .04 \mathrm{~N} \\
.04 \mathrm{~N} & .04 \mathrm{~N} & .04 \mathrm{~N} & .04 \mathrm{~N} & .04 \mathrm{~N} \\
.04 \mathrm{~N} & .04 \mathrm{~N} & .04 \mathrm{~N} & .04 \mathrm{~N} & .04 \mathrm{~N} \\
.04 \mathrm{~N} & .04 \mathrm{~N} & .04 \mathrm{~N} & .04 \mathrm{~N} & .04 \mathrm{~N}
\end{array}\right]
$$

These expected frequencies under time-independence $E X P_{i j}$ may then be compared with the observed frequencies $O B S_{i j}$ by calculating the standard (Pearson) chi-squared statistic:

$$
\chi^{2}=\sum_{i} \sum_{j} \frac{\left(O B S_{i j}-E X P_{i j}\right)^{2}}{E X P_{i j}}
$$

Note that the chi-squared statistic is highest the further the economy is from time-independence, and in this sense chi-squared measures immobility. In order to have a statistic that measures mobility, a measure is needed that increases as the economy gets closer to time-independence. One such measure is minus chi-squared; it is used below.

The chi-squared statistic is not the only measure of time-dependence. Standard statistical packages contain contingency table procedures that produce quite a number of independence statistics. For instance, in addition to producing a chi-squared value, Stata also generates the likelihood-ratio chi-squared, Cramer's V, gamma, and Kendall's tau-b. And, if the researcher has access to the micro data from which the quantile transition matrix has been constructed, s/he can also calculate the Pearson correlation coefficient or the Spearman rank correlation coefficient. Note that all of these indices take on higher values the more immobile the underlying situation is. Indices of this kind have been calculated by Friedman and Kuznets (1954), Schiller (1977), Atkinson et al. (1992), Hungerford (1993) and OECD (1996, 1997), among others. In order to make higher values correspond to greater mobility, some authors have proposed using 1 minus the correlation between incomes (e.g., Department of Employment 1973) or 1 minus the correlation between log-incomes (Hart 1981). The intergenerational earnings elasticity calculated for many countries around the world (Solon, 2002) also is a measure of time-dependence.

\section{Positional movement}

According to this notion of mobility, an individual is deemed to have experienced mobility if and only if $\mathrm{s} / \mathrm{h}$ changes position in the income distribution. Although the most commonly used measures of economic position are individuals' quintiles or deciles in the income distribution, there is no reason why ventiles, centiles, or even ranks might not be used instead. 
Positional-movement indices then gauge the extent to which positions change in a population or a sample. Many researchers have used the immobility ratio (namely, the fraction of cases lying along the principal diagonal), while others have used the mean number of quantiles moved (in absolute value), the mean upward jump, and the like (Boudon 1973; Lillard and Willis 1978; Gottschalk 1982; Atkinson et al. 1992; and OECD 1996, 1997). A sophisticated positional movement index was developed axiomatically by King (1983).

Observe that the notion of positional movement is thoroughly relative: a person can experience relative income mobility even if his/her own income does not change, provided that others' incomes change by enough that the person in question experiences a change in position. There is another way in which a person can experience relative income mobility even if his/her own income remains unchanged, and that is through share movement.

\section{Share movement}

Some mobility analysts, even thoroughgoing relativists, are concerned primarily about changes in income ratios rather than with changes in positions within the income distribution. Suppose one person's income rises by 50 per cent but everyone else's rises by 100 per cent. The analyst may feel that the first person has lost ground, because his/her income share has fallen. From the perspective of share movement, the first person may indeed be judged to have experienced downward mobility, not because that person's income has fallen (because in this example, it has not) but because that person's share of total income has fallen.

To gauge the extent of share-movement in a population, the mean share movement will not work as an index. This is because the income shares must sum to 100 per cent, and therefore the changes in shares must necessarily average out to zero. What would work as an index of share movement is the mean absolute value of share changes. This measure is used later.

Inadvertently, a measure of share movement is commonly calculated. It can readily be shown that the correlation between base year and final year incomes is the same as the correlation between base year and final year income shares. Thus, the correlation coefficient frequently calculated from micro data can be viewed as an (inverse) index of share movement.

Chakravarty et al. (1985) analyzed the issue of relative income mobility using ethical (welfarist) foundations. For them, an initial distribution of income exhibits complete relative immobility if and only if the income shares are the same for all individuals in all time periods. They then derived the following share movement index: $M_{C D W}=\left(\left(E Y_{a}\right) / E\left(Y_{1}\right)\right)-1$, where $E\left(Y_{a}\right)$ is an index of equality of average incomes and $E\left(Y_{1}\right)$ is an index of equality of incomes in period one. For them, the mobility index is positive (negative), and therefore the mobility process is desirable (undesirable), if and only if average incomes are more (less) equally distributed than initial incomes were. 
Thus, Chakravarty et al. (1985) assign welfare significance only to the relative aspect of changes in incomes while ignoring whether incomes are rising or falling, a judgement that many would find objectionable.

What share-movement measures is flux; that is, how much variation there is between base year and final year. Here, the aspect of flux that is being measured is income shares, whereas on pp. 128-9, it was positions in the income distribution. For those observers who are interested in flux, but who are more concerned about incomes than shares or positions, the next class of measures may be appealing.

\section{Income flux (also called 'instability' or 'non-directional income movement')}

Consider two persons, one of whom experiences a $\$ 10,000$ income gain and the other a $\$ 10,000$ income loss. How much income movement has taken place? A respondent who answers that the total income movement is $\$ 20,000$ total or $\$ 10,000$ per capita has used an income flux measure, in the sense that the gains and losses are weighted similarly without regard to the direction of change. Precisely, this measure was devised and justified axiomatically by Fields and Ok (1996). Specifically, the first Fields-Ok per capita measure is

$$
m_{n}^{(1)}(x, y)=\frac{1}{n} \sum_{j=1}^{n}\left|x_{i}-y_{i}\right|
$$

that is, the mean absolute income change. This index makes the implicit assumption that a dollar gain or loss is the same regardless of the income level of the person experiencing it. To the contrary, one may want to consider a dollar change differently depending on how rich or poor the person was initially - specifically, by regarding a given dollar amount of change as counting for less the richer is the income recipient. A measure that was derived axiomatically and shown to possess this property is the second per capita measure proposed by Fields and Ok (1999b):

$$
m_{n}^{(2)}(x, y)=\frac{1}{n} \sum_{j=1}^{n}\left|\log x_{i}-\log y_{i}\right|
$$

Income flux has also been gauged in studies by Abowd and Card (1989), Gottschalk and Moffitt (1994) and Stevens (2001), among others.

\section{Directional income movement}

An observer may be more interested in the directions and magnitudes of income changes than in absolute values. For such an observer, the concept of interest is directional income movement. 
Several ad hoc directional indices are in use, such as the fraction of upward or downward movers, the average amount gained by the winners, and the average amount lost by the losers. Moving beyond these ad hoc measures, Fields and Ok (1999b) axiomatized directional income movement and devised as a measure the mean change in log-incomes:

$$
m_{n}^{(3)}(x, y)=\frac{1}{n} \sum_{j=1}^{n}\left(\log x_{i}-\log y_{i}\right)
$$

This measure combines income gains and losses taking account of the income levels of each of the gainers and each of the losers.

\section{Mobility as an equalizer of longer-term incomes relative to the base}

One of the primary motivations for economic mobility studies is to gauge the extent to which longer-term incomes are distributed more or less equally than are single year incomes. Slemrod (1992), for instance, has maintained that what he graphically calls 'time-exposure income' gives a better picture of inequality than does 'snapshot income'. Continuing in a similar vein, Krugman (1992) has written: 'If income mobility were very high, the degree of inequality in any given year would be unimportant, because the distribution of lifetime income would be very even... An increase in income mobility tends to make the distribution of lifetime income more equal'. Similar statements have been made by, among others, Shorrocks (1978), Maasoumi and Zandvakili (1986), Atkinson et al. (1992) and Jarvis and Jenkins (1998).

What unites these and other authors is a concern with income mobility as an equalizer of longer-term incomes along with the judgement that the extent of such equalization is of ethical relevance. In Fields (2004), it is shown that although the established mobility measures do a good job of measuring other mobility concepts, they do not adequately gauge this one. ${ }^{4}$

In the absence of a good measure of this concept, a new class of measures representing this concept were worked out. One easily implementable measure in this class is the equalization measure

$$
\mathrm{E} \equiv 1-\left(\mathrm{I}(\mathrm{a}) / \mathrm{I}\left(\mathrm{Y}_{1}\right)\right)
$$

where $\mathrm{a}$ is the vector of average incomes, $\mathrm{Y}_{1}$ is the vector of base year incomes, and $I($.$) is an inequality measure. .^{5}$ When incomes over a longer period are distributed as unequally as base year incomes are, $\mathrm{E}=0$. When incomes over a longer period are distributed more equally than base year incomes, $\mathrm{E}>0$, signifying that the income mobility that took place caused longerterm incomes to be more equally distributed than were base year incomes. Lastly, when incomes over a longer period are distributed less equally than base year incomes, $\mathrm{E}<0$; that is, the pattern of changes has been in the disequalizing direction. 
Six mobility concepts have been presented in this section: timeindependence, positional movement, share movement, income flux, directional income movement, and mobility as an equalizer of longer-term incomes relative to the base. Because each of these concepts is different from the others, a measure of one concept does not necessarily accord with the measure of another. Whether they give the same qualitative answers in practice is an empirical question, to which we now turn.

\section{Comparing the mobility concepts}

Consider how two or more mobility situations compare with one another. Which has more mobility? That different mobility indexes can produce different ordinal rankings is well-known; see for instance Dardanoni (1993), Maasoumi (1998) and Checchi and Dardanoni (2003). What is unclear, though, is whether the different indexes produce different ordinal rankings because they are gauging fundamentally different concepts (as, for example, income inequality is a fundamentally different concept from poverty) or because they produce different ordinal rankings for the same concept (as, for example, may arise for two different Lorenz consistent inequality indexes when Lorenz curves cross).

Let us compare the six mobility concepts, using one index of each. These indices are defined formally in Table 6.1. Statistical software for calculating a number of these indices (and others) is available in Van Kerm (2002).

Table 6.1 Measures of six mobility concepts used in the empirical work

\section{Concept}

Time-independence

Positional-movement

Per capita share movement

Per capita income flux

Per capita directional movement

Mobility as an equalizer of longerterm income

\section{Measure used in the two-period case}

$1-r\left(y_{1}, y_{2}\right)$, where $r$ is the Pearson correlation coefficient

$1-\rho\left(\mathrm{y}_{1}, \mathrm{y}_{2}\right)$, where $\rho$ is the rank correlation coefficient

$(1 / n) \Sigma\left|s\left(\mathrm{y}_{2 \mathrm{i}}\right)-\mathrm{s}\left(\mathrm{y}_{1 \mathrm{i}}\right)\right|$, where $\mathrm{s}($.$) denotes i's$ share of total income

$(1 / n) \Sigma\left|y_{2 \mathrm{i}}-\mathrm{y}_{1 \mathrm{i}}\right|$

$(1 / n) \Sigma\left(\log y_{2 \mathrm{i}}-\log \mathrm{y}_{1 \mathrm{i}}\right)$

$E \equiv 1-\left(\mathrm{I}(\mathrm{a}) / \mathrm{I}\left(\mathrm{Y}_{1}\right)\right)$, where $\mathrm{a}$ is the vector of average incomes, $Y_{1}$ is the vector of base year incomes, and $\mathrm{I}($.) is an inequality measure (either the Gini coefficient or the Theil index) 
How do the six mobility concepts compare in the two examples?

First, let us take the hotel example, in which guests move between rooms of different quality from one night to the next. Because guests are switching rooms and some rooms are better than others, there is not perfect timedependence. ${ }^{6}$ The movements among rooms of different quality means that positional movement takes place, as does share movement. There is flux, because some guests experience different rooms of different quality. Those who move up in the hotel experience upward directional movement; the opposite is the case for those moving down in the hotel. Finally, because the average quality experienced over a number of nights is distributed more equally than the quality on the first night or on any other night, mobility has equalized longer-term outcomes relative to any given night's distribution.

Consider next the two-person income example. Either the personalized change was

(a) $(1,3) \rightarrow(1,5)$

$\alpha \beta \quad \alpha \beta$

or it was

(b) $(1,3) \rightarrow(5,1)$

$\alpha \beta \quad \alpha \beta$

Here, the recipients' names (in Greek letters) have been inserted so that it is easier to talk about who is who.

What has happened in Case (a)? There is perfect time-dependence in ranks but not in incomes. There has been no positional movement. There has been share movement, upward in the case of individual $\beta$ and downward in the case of individual $\alpha$. Incomes changed and therefore income flux took place; its average absolute value was $\$ 1$. As for directional income movement, income growth took place for individual $\beta$ but not for individual $\alpha$. Finally, the distribution of average income over the longer term is $(1,4)$, which is more unequal than the base year distribution $(1,3)$. Mobility therefore disequalized longer-term incomes relative to base year incomes.

What if the underlying situation had been that of Case (b)? In this case, some of the preceding indicators are the same and some are different. Once again, there is perfect time-dependence in ranks but not in incomes, but this time the dependence is negative, not positive. Now, there has been positional movement. There also have been share movements. Income flux took place; now, its average magnitude is $\$ 3$. Directional income movements took place for both individuals in this case, upward for individual $\alpha$ and downward for individual $\beta$. Finally, the distribution of average income over the longer term is $(3,2)$, which is more equally distributed than either base year or final year 
income, and mobility therefore equalized longer-term incomes relative to base year incomes.

This subsection has asked: Was there mobility in the hotel? Was there mobility in the two-person economy? In each case, what was its nature? The answers to these questions have been shown to depend on which mobility concept is used. As shall now be demonstrated, different conclusions on the nature of mobility also arise in empirical applications for the United States and France.

\section{How do the six mobility concepts compare in two country cases?}

Examples have been given showing that the six mobility concepts can convey different impressions from one another. This subsection shows that different concepts also produce different patterns in actual countries' experiences.

The first empirical application is from the United States. Measures of the six concepts are used to gauge five-year income mobility from 1970-75 to 1990-95. Data are drawn from the Panel Study of Income Dynamics on earnings (including overtime and bonuses) for men aged 25-60 in the base year who were not students, retired or self-employed and who had positive earnings in both years. Further details are presented in Fields et al. (2000) and Fields (2004).

Figure 6.1 plots the time paths of five-year earnings mobility (in real dollars) for one measure of each of the six concepts, as presented in Table 6.1. Measures of time-independence, positional movement, share movement, and income flux are all seen to exhibit the same pattern: rising until 1980-85, falling thereafter. However, these time paths do not hold for the other two concepts. The measure of directional income movement exhibits a saw-tooth pattern. On the other hand, the measure of mobility as an equalizer of longerterm incomes exhibits a peak followed by a valley. Moreover, this last measure crossed over from positive values in the 1970 s to zero or negative values in the 1980 s and 1990s. In other words, earnings mobility among US men acted to equalize longer-term incomes relative to base year income in the 1970s and stopped doing so since. So, contrary to Krugman's conjecture and the others cited above, mobility may not be making the distribution of longer-term income more equal in the United States any longer.

A second empirical application is from France, drawing on the work of Buchinsky et al. (2003). The French data come from employers' declarations to the government of wages and salaries paid to each of their employees (now known as the Déclarations Annuelles de Données Sociales, formerly called the Déclarations Annuelles de Salaires). These data were merged with the information on sex, age and education level from the government's demographic registry (Echantillon Démographique Permanent). Two-year mobility in real francs was calculated beginning in 1967-69 and ending in 1997-99. 
Time-independence

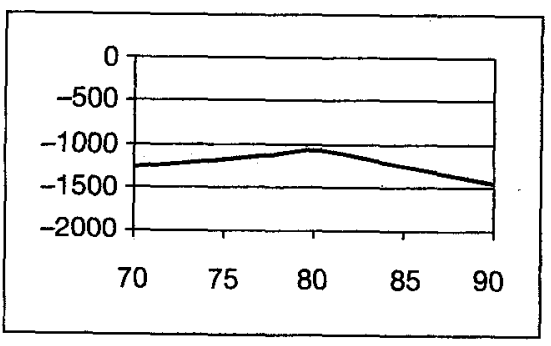

Income flux

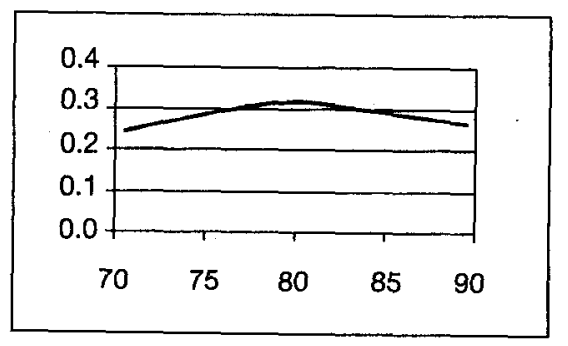

Positional movement

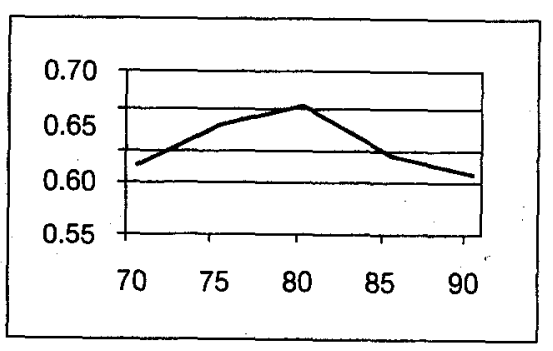

Directional income movement

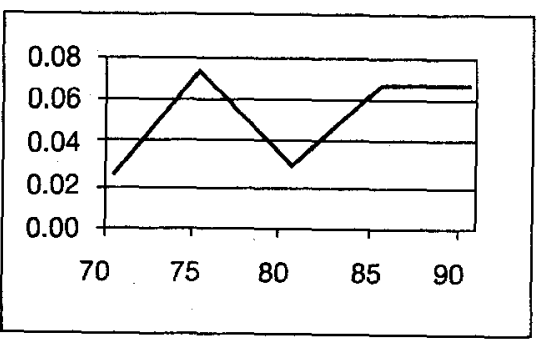

Share movement

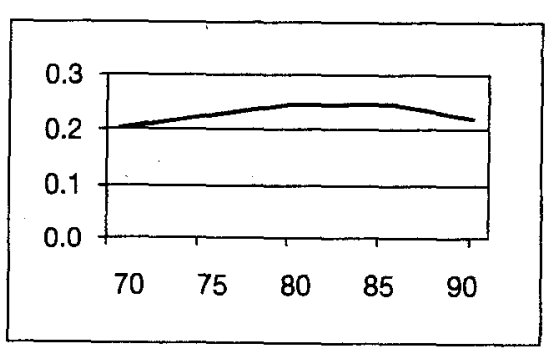

Mobility as an equalizer of longer-term incomes

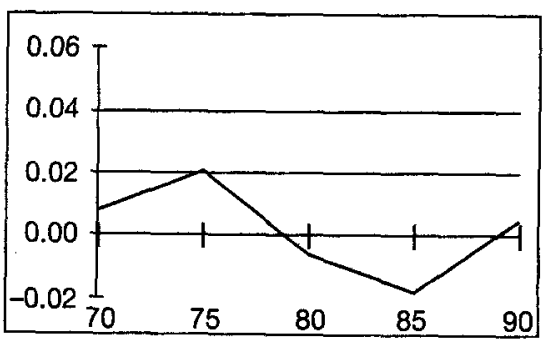

Figure 6.1 United States: evolution of earnings mobility, 1970-95 
The first question for France is the same as for the US: How did mobility evolve over time for each of these six mobility concepts? In this case, Figure 6.2 demonstrates that measures of the first five mobility concepts all exhibit the same pattern: higher mobility at the beginning, followed by a sharp drop, and then a levelling-off at a new lower level. However, the sixth mobility concept - mobility as an equalizer of longer-term income - shows a different pattern. This type of mobility reversed course and has now reached its earlier levels. Note, too, that in France, unlike the United States, these values are always positive; that is, two-year average earnings have always been more equally distributed than base year earnings were.

The second and third questions for France concern demographic differences. Who has more mobility: women or men; better educated or less educated workers? The data are presented in Figures 6.3 and 6.4. For both questions, the answers differ depending on which mobility concept is used. By gender, women have more time-independence and positional movement than men, less share movement than men, about the same flux and directional movement in logs, and about the same amount of mobility as an equalizer of longer-term incomes. By education, those with the highest educational attainments have less time-independence and positional movement and, if anything, more share movement, flux, and directional income movement in logs. Finally, mobility equalized longer-term incomes less for the best educated and moderately educated than for the least educated in the early years, but this difference appears to have disappeared more recently.

In summary, these results for the United States and France show that the different mobility concepts produce qualitatively different empirical patterns. For some mobility concepts, mobility has fallen over time; for others, it has not. For some mobility concepts, women have more mobility than men; for others, men have more mobility than women. For some mobility concepts, mobility rises with education; for others, it falls.

These different results imply that researchers must be very cautious before saying that mobility is higher here than there, for this group as compared with that group, or now as compared with before. Mobility studies must specify which mobility concept, or concepts, is under discussion. Rather than talking about 'mobility', analysts would be able to communicate more effectively if we were to speak in terms of 'positional movement', 'income flux', or whatever. Let analysts decide which aspect(s) of mobility is (are) of greatest interest and choose the mobility indices accordingly. As these empirical results demonstrate, it does make a difference which concept(s) one chooses to measure. 
Time-independence
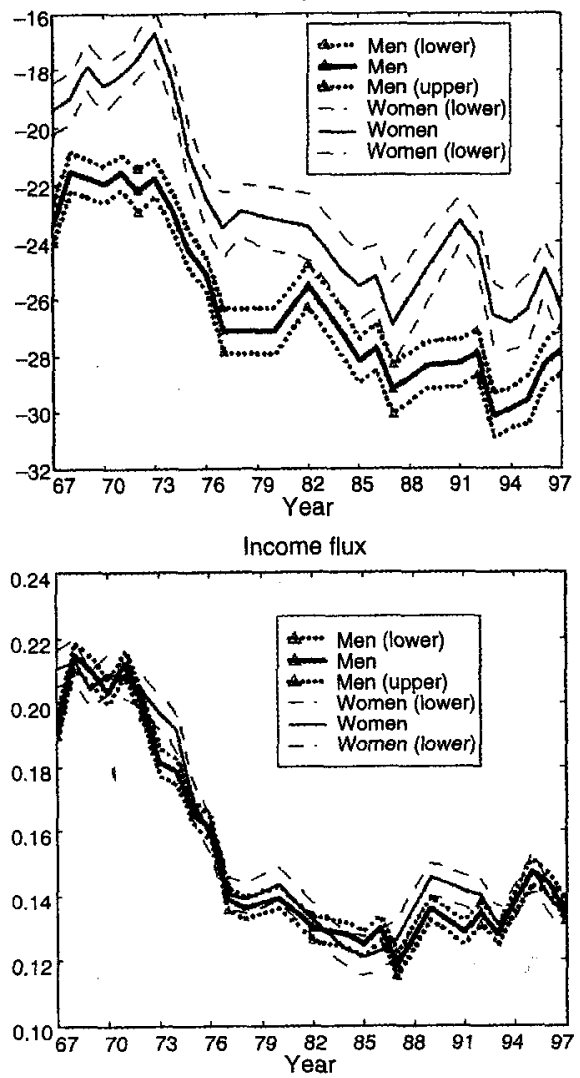

Positional movement

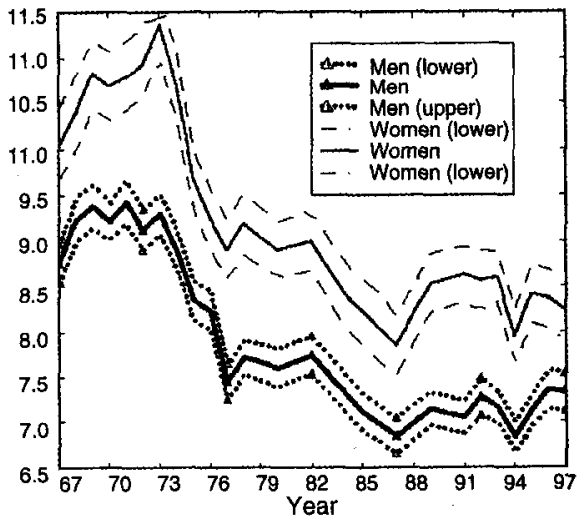

Directional income movement

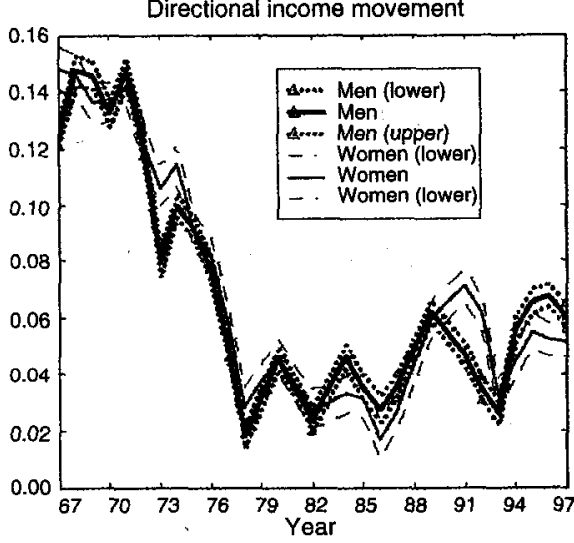

Share movement

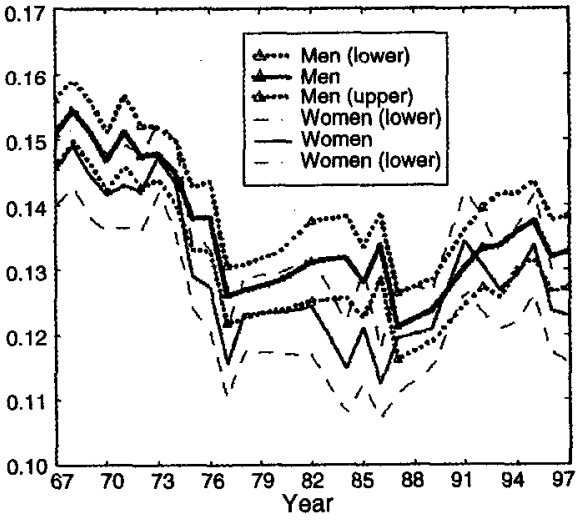

Mobility as an equalizer of longer-term incomes

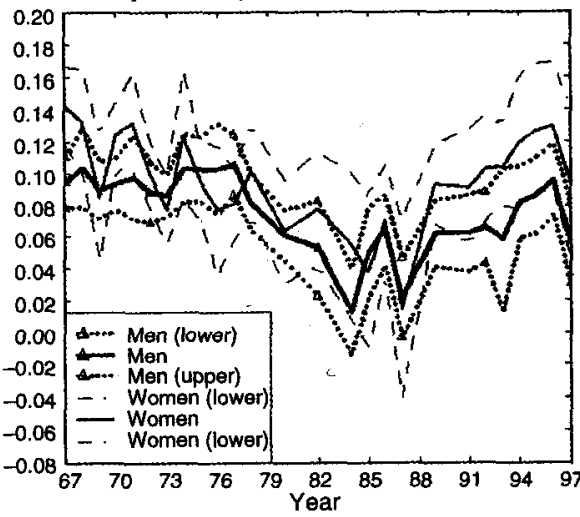

Figure 6.3 France: evolution of wage mobility, 1967-99, by gender (with 95 per cent confidence intervals) 

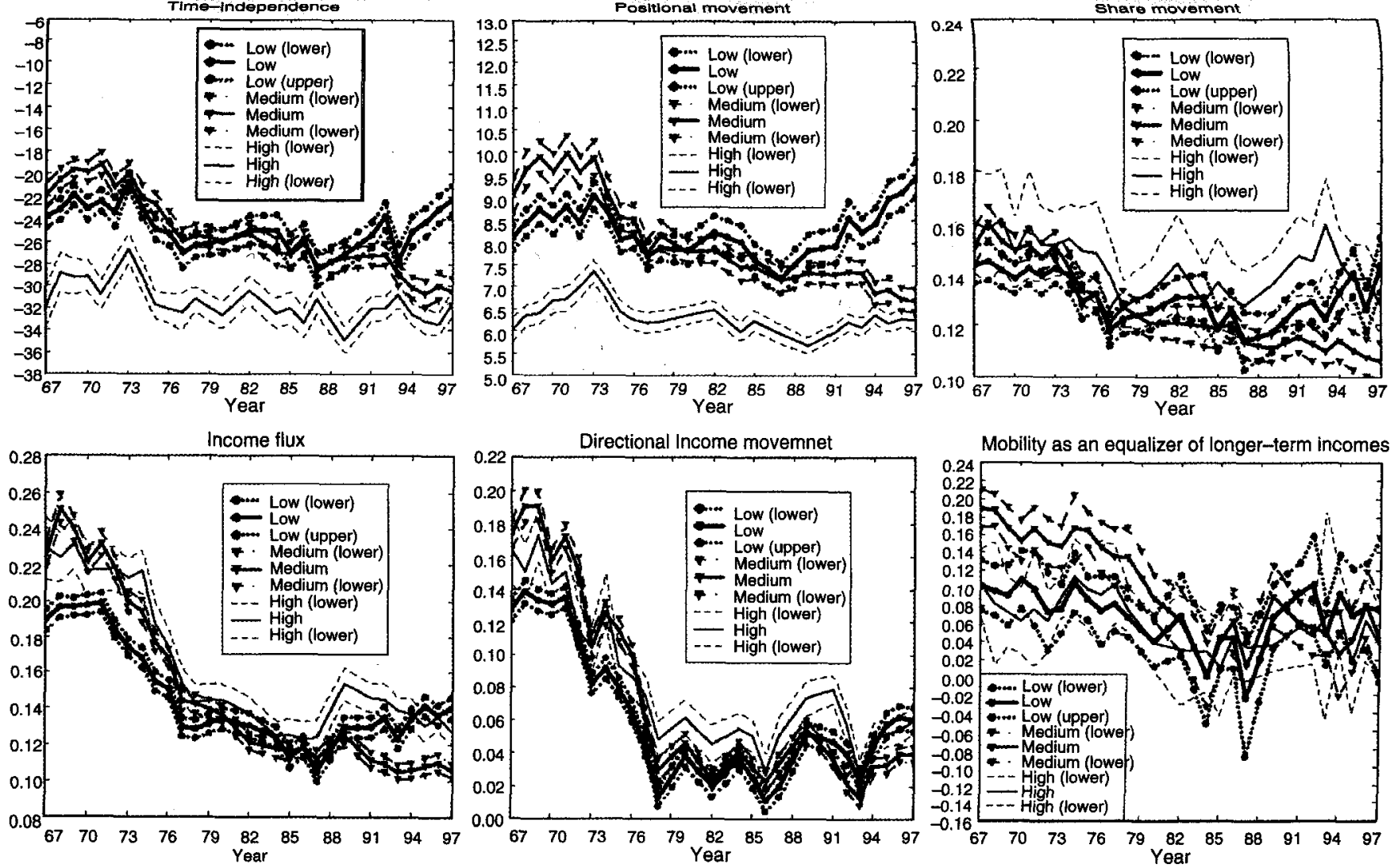

Mobility as an equalizer of longer-term incomes

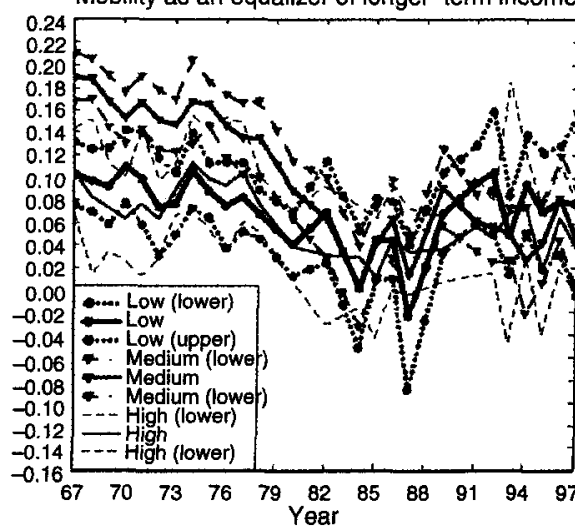

Figure 6.4 France: evolution of wage mobility, 1967-99, by education (low: primary or junior high sch.; medium: technical sch.; high secondary dipl. (baccalaureat and beyond) 


\section{Conclusion}

This chapter demonstrated that economic mobility truly is multifaceted. The six facets are time-independence, positional movement, share movement, flux, directional income-movement, and mobility as an equalizer of longerterm incomes. These six concepts were explored, and it was shown that they can produce very different qualitative answers to such basic questions as whether economic mobility is increasing or decreasing over time, whether women have more or less economic mobility than men, and whether the better educated have more or less mobility than those with less education.

It follows that mobility comparisons can only be made once the mobility concept under examination has been made precise. An unqualified statement of the form 'Mobility is higher in $A$ than in $B^{\prime}$ ' is as vague and meaningless as saying that 'Income distribution is better in $X$ than in $Y^{\prime}$ '. In the same way that researchers have learned to talk about which aspect of the income distribution is better in $X$ than in $Y$ (for example, location, dispersion or economic wellbeing) according to a particular measure of that aspect, researchers also need to learn to talk about which aspect of mobility is higher in $A$ than in $B$.

The various mobility concepts used in the literature differ from one another in ways that are only imperfectly understood. Likewise, the various measures of a given concept also differ from one another in ways that are only imperfectly understood. A task for future research would be to explore these differences and systematize them.

\section{Notes}

1. The original citation is Schumpeter (1955: 126). Schumpeter is cited in Sawhill and Condon (1992) and Danziger and Gottschalk (1995). Jarvis and Jenkins (1996) use the same analogy.

2. Surveys of the literature on economic mobility may be found in Atkinson et al. (1992), Maasoumi (1998), Fields and Ok (1999a) and Morgan (2005).

3. It might be better to say nothing believable can be learned from such anonymous data. Some researchers have not been content to say nothing when only anonymous data are available, instead making assumptions as to how particular individuals' incomes change in comparable cross-sections. The answers merely reflect the assumptions maintained in deriving them. The results of such exercises are literally unbelievable and should be given no credence.

4. In particular, the measure proposed by Shorrocks (1978) and generalized by Maasoumi and Zandvakili (1986) gauges the inequality of longer-term incomes relative to the weighted average of inequality in each period, not inequality in the base period. On the other hand, while the index proposed by Chakravarty et al. (1985) does relate the inequality of longer-term incomes to inequality in the base period, when they put their index to use, they assign welfare significance only to the change in inequality and not to any change in the level of income. See Fields (2004) for further discussion.

5. In the empirical work below, the Gini coefficient is used for the United States, and Theil's L index for France. 
6. Rejecting perfect time-dependence does not mean that we do or do not have perfect time-independence. Whether we do or not depends on whether all guests are randomly assigned to rooms night after night or whether the assignment one night is linked to the previous assignment.

\section{References}

Abowd, J.M. and D. Card (1989) 'On the Covariance Structure of Earnings and Hours Changes', Econometrica, 57, 411-45.

Atkinson, A.B., F. Bourguignon and C. Morrisson (1992) Empirical Studies of Earnings Mobility (Chur, Switzerland: Harwood).

Boudon, R. (1973) Mathematical Structures of Social Mobility (Amsterdam: Elsevier).

Buchinsky, M., G.S. Fields, D. Fougère and F. Kramarz (2003) Francs or Ranks? Earnings Mobility in France, 1967-1999, INSEE/CREST, processed.

Chakravarty, S.R., B. Dutta and J.A. Weymark (1985) 'Ethical Indices of Income Mobility', Social Choice and Welfare, 2, 1-21.

Checchi, D. and V. Dardanoni (2003) 'Mobility Comparisons: Does Using Different Measures Matter?', Research on Economic Inequality, 9, 113-45.

Danziger, S. and P. Gottschalk (1995) America Unequal (New York: Harvard University Press and the Russell Sage Foundation).

Dardanoni, V. (1993) 'Measuring Social Mobility', Joumal of Economic Theory, 61, 372-94.

Department of Employment (UK) (1973) 'Low Pay and Changes in Earnings', Employment Gazette, April, 335-48.

Fields, G.S. (2004) Does Income Mobility Equalize Longer-Term Incomes? New Measures of an Old Concept, Cornell University, processed.

Fields, G.S., J.B. Leary and E.A. Ok (2000) Dollars and Deciles: Changing Earnings Mobility in the United States, 1970-1995, Cornell University, processed.

Fields, G.S. and E.A. Ok (1996) 'The Meaning and Measurement of Income Mobility', Journal of Economic Theory, 71, 349-77.

Fields, G.S. and E.A. Ok (1999a) 'The Measurement of Income Mobility: An Introduction to the Literature', in J. Silber (ed.), Handbook of Income Distribution Measurement, (Amsterdam: Kluwer).

Fields, G.S. and E.A. Ok (1999b) 'Measuring Movement of Income', Economica, 66, 455-72.

Friedman, M. and S. Kuznets (1954) Income from Independent Professional Practice (New York: NBER).

Gottschalk, P. (1982) 'Earnings Mobility: Permanent Change or Transitory Fluctuations?', Review of Economics and Statistics, 64, 450-6.

Gottschalk, P. and R. Moffitt (1994) 'The Growth of Earnings Instability in the U.S. Labor Market', Brookings Papers on Economic Activity, 2, 217-72.

Hart, P.E. (1981) 'The Statics and Dynamics of Income Distribution: A Survey', in N.A. Klevmarken and J.A. Lybeck (eds), The Statics and Dynamics of Income (Tieto: Clevedon).

Hungerford, T.L. (1993) 'U.S. Income Mobility in the Seventies and Eighties', Review of Income and Wealth, 39, 403-17.

Jarvis, S. and S.P. Jenkins -(1996) 'Changing Places: Income Mobility and Poverty Dynamics in Britain', University of Essex Paper 96-19, processed.

Jarvis, S. and S.P. Jenkins (1998) 'How Much Income Mobility Is There in Britain?', Economic Journal, 108, 1-16. 
King, M.A. (1983) 'An Index of Horizontal Inequality: with Applications to Horizontal Equity and Social Mobility', Econometrica, 51, 1, 99-115.

Krugman, P. (1992) 'The Rich, the Right, and the Facts', American Prospect, 3, 11, 19-31. Available at: http://www.prospect.org/print/V3/11/krugman-p.html

Lillard, L.A. and R.J. Willis (1978) 'Dynamic Aspects of Eamings Mobility', Econometrica, $46,985-1012$.

Maasoumi, E. (1998) 'On Mobility', in D. Giles and A. Ullah (eds), Handbook of Applied Economic Statistics (New York: Marcel Dekker) pp. 119-76.

Maasoumi, E. and S. Zandvakili (1986) 'A Class of Generalized Measures of Mobility with Applications', Economics Letters, 22, 97-102.

Morgan, S.L. (2005) 'Past Themes and Future Prospects for Research on Social and Economic Mobility', in S.P. Morgan, D.B. Grusky and G.S. Fields (eds), Mobility and Inequality: Frontiers of Research from Sociology and Economics (Palo Alto, CA: Stanford University Press).

OECD $(1996,1997)$ Employment Outlook (Paris: OECD).

Sawhill, I.V. and M. Condon (1992) 'Is U.S. Income Inequality Really Growing?', Policy Bites, 13, 1-4.

Schiller, B. (1977) 'Relative Earnings Mobility in the U.S.', American Economic Review, December, 926-41.

Schumpeter, J. (1955) Imperialism and Social Classes (New York: Meridian Books).

Shorrocks, A.F. (1978) 'Income Inequality and Income Mobility', Journal of Economic Theory, 19, 376-93.

Slemrod, J. (1992) 'Taxation and Inequality: A Time-Exposure Perspective', in J.M. Poterba (ed.), Tax Policy and the Economy, 6 (Cambridge MA: MIT Press for the NBER) 105-27.

Solon, G. (2002) 'Cross-Country Differences in Intergenerational Earnings Mobility', Journal of Economic Perspectives, 16, 3: 59-66.

Stevens, A.H. (2001) 'Changes in Earnings Instability and Job Loss', Industrial and Labor Relations Review, 55, 60-78.

Van Kerm, P. (2002) 'Tools for the Analysis of "Income Mobility" in Stata'. Available at: http://ideas.repec.org/p/boc/dsug02/9.html 